\title{
COMO OS AGRICUTORES FAMILIARES PERCEBEM A QUESTÃO AMBIENTAL?
}

\author{
Cristiane Maria Tonetto Godoy ${ }^{1}$ \\ José Geraldo Wizniewsky \\ Aline Guterres Ferreira
}

\begin{abstract}
Resumo
Desde a Revolução Industrial o desenvolvimento econômico baseia-se na utilização dos recursos naturais e dos recursos não-renováveis, causando impactos ambientais e a perda da biodiversidade, gerando problemas para os seres vivos como um todo. Diante dessa problemática têm-se aumentado os debates sobre a necessidade da preservação do meio ambiente e da sustentabilidade ambiental como garantia da própria perpetuação e preservação do ser humano. A Legislação Ambiental Brasileira contêm as leis e as normas que pretendem assegurar a manutenção da biodiversidade e a preservação ambiental nas propriedades rurais. O presente trabalho teve como objetivo compreender a percepção dos agricultores familiares do município de Santa Rosa/RS quanto à importância da preservação ambiental, focando mais especificamente as áreas de reserva legal e áreas de preservação permanente.
\end{abstract}

Palavras-chave: Educação Ambiental, Agricultura Familiar, Percepção Ambiental, Sustentabilidade

\section{INTRODUÇÃO}

O reconhecimento da crise e dos impactos ambientais gerados pela produção industrial, o consumo e a agricultura intensiva estão em pauta de diversas políticas públicas. Neste sentido, o consumo exagerado por produtos provenientes da indústria geram resíduos que ao serem descartados se acumulam no meio ambiente, além da economia estar fundamentada na utilização de matérias-primas escassas tem sido uma das maiores preocupações da sociedade contemporânea, pelas degradações/contaminações provenientes deste estilo de vida e economia, que acabam por colocar em risco a sustentabilidade da biodiversidade e dos ecossistemas.

O processo Revolução Verde (RV) na agricultura é apontado como o principal transformador das práticas agrícolas/pecuárias, conseqüentemente é visto como o fator responsável pela degradação ambiental e social no meio rural. As melhorias provenientes da Revolução Verde tinham como propósito o aumento da produtividade agrícola, por meio da substituição dos modelos de produção tradicional por um conjunto

1 Eng. Agrônoma, Doutoranda do Programa de Pós-Graduação em Extensão Rural da Universidade Federal de Santa Maria - UFSM- ctgextr@hotmail.com; Eng. Agrônoma, Professor Associado do Departamento de Educação Agrícola e Extensão Rural da Universidade Federal de Santa Maria; Zootecnista, Mestranda do Programa de Pós-Graduação em Extensão Rural da Universidade Federal de Santa Maria. 
homogêneo de práticas tecnológicas, culminando nos problemas que até hoje são percebidos no meio rural, tais como: monocultivos, êxodo rural, endividamento dos agricultores, masculinização, problemas de saúde pelo uso de agrotóxicos.

De acordo com Zaneti e Sá (2002), a apropriação privada dos recursos naturais está norteada pela lógica capitalista, privilegiando principalmente a busca pelo lucro, com um sistema produtivo artificial linear e em crescente aceleração, assim, é o fator principal pela crise ambiental vivida atualmente pela sociedade, além de gerar uma enorme quantidade de resíduos provenientes da produção e do consumo dos produtos. As autoras citadas, ainda afirmam que o esgotamento dos recursos naturais e a presente necessidade de encontrar formas e soluções para evitar o colapso ambiental irão explicar o crescente movimento da sociedade para formulação de um novo paradigma, o desenvolvimento sustentável.

Segundo Jacobi (2003), a dimensão ambiental encontra-se envolvida por um conjunto de atores; pelos diversos sistemas de conhecimentos; capacitação de profissionais e de centros acadêmicos e pelas diversas esferas da sociedade, numa perspectiva de interdisciplinaridade entre os agentes envolvidos. A produção do conhecimento deve contemplar as inter-relações do meio natural-social-econômico, incluindo no processo análises determinante e o papel dos diversos atores e as formas de organizações, aumentando o poder das ações alternativas para um novo desenvolvimento fundamentado na sustentabilidade social, ambiental e econômica.

A educação ambiental deve ser proposta a partir da transdisciplinariedade entre os contextos sociais, ambientais, econômicos e escolares, formando uma perspectiva integradora entre estes fatores. Neste sentido, é que a educação ambiental visa contribuir e assegurar um novo paradigma, promovendo a conscientização dos agricultores familiares, resgatando a identidade e a cidadania através da participação destes nos processos de decisão/ação de alternativas para a conservação ambiental. Este resgate se deve pela sua participação efetiva na melhoria da qualidade de vida da sociedade e na sustentabilidade que tanto se deseja atualmente.

Buscou-se neste trabalho compreender a percepção dos agricultores familiares das localidades rurais de: Candeia Baixa, Lajeado Paulino, Lajeado Pessegueiro e Rincões, do município de Santa Rosa/RS, quanto à importância da preservação ambiental, focando mais 


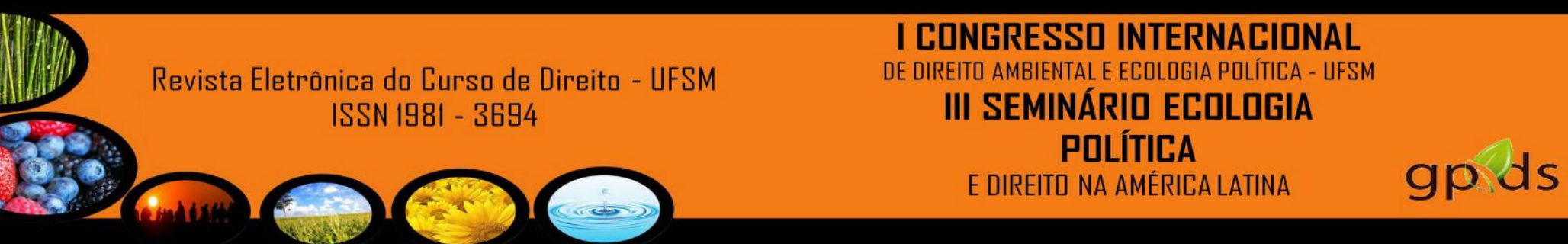

especificamente na presença das áreas de reserva legal e áreas de preservação permanente encontradas nas propriedades.

\section{CONTEXTUALIZANDO SOBRE O TEMA}

\section{1- Agricultura Familiar}

A agricultura familiar não deve ser considerada como um termo novo ou uma nova classe rural, entretanto, seu uso é recente, principalmente nos meio acadêmicos, nas políticas governamentais e movimentos sociais, adquirindo assim novos significados.

Em sua obra Chayanov (1974), analisa a organização da atividade econômica da agricultura familiar, como uma família que não contrata força de trabalho externa e que tem certa extensão de terra disponível, seus próprios meios de produção e que, às vezes, se vê obrigada a empregar parte da sua força de trabalho em atividades rurais não agrícolas. Para o autor, a lógica do campesinato é diferente da lógica da empresa capitalista, o agricultor familiar realiza o trabalho com o objetivo de satisfazer as necessidades da sua família, uma vez que estas necessidades estejam asseguradas, se atribuí um valor cada vez menor para cada unidade adicional de trabalho, já a empresa capitalista maximiza as unidades adicionais visando o lucro.

Segundo Wanderley (2000), a agricultura familiar não pode ser entendida como uma nova classe ou uma nova categoria social, ou que o seu surgimento seja recente. Mas, no Brasil, esta conceituação assume ares de novidade e de renovação quanto ao seu significado e abrangência, principalmente nos meios acadêmicos e nas políticas públicas que passam a estimular a criação de tipologias baseadas na viabilidade econômica e social diferenciada.

A agricultura familiar tem sido alvo de interesses de políticas públicas e do governo, um marco neste sentido, foi o reconhecimento da categoria agricultura familiar em julho de 2006, através da Lei ${ }^{\circ} 11.326$, que estabelece os conceitos, princípios e instrumentos destinados à formulação das políticas públicas direcionadas à Agricultura 

no Brasil, ficou conhecido como Relatório de Brundtland, publicado em 1987 com o título de "Nosso Futuro Comum".

O desenvolvimento sustentável deve ser entendido como "aquele desenvolvimento que atende às necessidades do presente sem comprometer as possibilidades de as gerações atenderem às suas próprias" (RELATÓRIO DE BRUNDLANT, 1987).

Esta mudança de paradigma, segundo Capra (1996), deve ser uma visão de mundo holística, concebendo que o mundo é todo integrado e não uma coleção de partes dissociadas e reducionistas. O homem não está situado acima ou fora da natureza e sim integrado a ela, ele é apenas um fio da extensa teia da vida, dependendo a sua sobrevivência da qualidade do meio ambiente.

Porém, para Mielgo e Guzmán (1994), no estudo intitulado “El Discurso Ecotecnocratico De La Sostenibilidad", os autores criticam o conceito de desenvolvimento sustentável que consta no Relatório de Brundtland (1987). Segundo os autores existe um falso discurso ecologista sendo divulgado pelas agências internacionais, através da construção teórica de pensamento de que o planeta esteja em perigo, entretanto, não é porque os países ricos se desenvolveram a custa de desperdícios na produção e no consumo de energia e recursos, mas sim, porque os países pobres têm um grande desenvolvimento populacional e que a "pobreza" desta população leva a degradação ambiental pela exploração dos recursos naturais.

A sustentabilidade não pode ser vista como um estágio final e sim como um processo contínuo capaz de se transformar ao longo do tempo. (ROBINSON, 1990 APUD DIEGUES, 1992)

As pressões socioeconômicas realizadas pela sociedade capitalista e que são legitimadas academicamente pela ciência econômica necessita de um novo paradigma, para que possamos assegurar a nossa sobrevivência nesse planeta. Um paradigma que vem sendo cada vez mais discutido e adotado seria a Agroecologia, que vem reconhecer que os sistemas sociais e ecológicos são inseparáveis. Nesse contexto, surge o termo ECOSOCIOLOGIA, que vem integrar a natureza e o homem. O exemplo de forma de produção que se encontra aliado nos dois termos (Agroecologia e Ecosociologia) seria a agricultura familiar, que irá integrar a natureza e homem, reduzindo o impacto ao meio ambiente e coexistindo com a natureza. A lógica da agricultura familiar não é pelo 
lucro, por isso se enquadra nesse novo paradigma. (MIELGO E GUZMÁN, 1994; GUZMÁN E NAVARRO, 2000)

Portanto, o desenvolvimento sustentável dever ser compreendido como aquele desenvolvimento com uma maior participação e mobilização da sociedade e governos na busca de um novo conceito de desenvolvimento, o qual está baseado em indicadores qualitativos e não mais quantitativos, bem como, alternativas mais sustentáveis ao longo prazo, promovendo assim um equilíbrio entre os diversos ecossistemas e biodiversidade existentes, garantindo a qualidade de vida e a perpetuação principalmente do homem, pois ele é um dos elementos integrados ao meio ambiente.

Neste sentido, surgem estratégias na busca pela sustentabilidade para consolidar este "novo" desenvolvimento e enfrentar a crise do esgotamento/degradação dos recursos naturais. Alguns exemplos de estratégias que podem ser utilizadas: as políticas públicas, a educação ambiental, o planejamento energético, o controle de poluição e de dejetos, entre outras, podendo ser ou não regulamentadas por leis e normas. A legislação existirá para regulamentar essas atividades, partindo do pressuposto que a garantia de qualidade de vida e a preservação do meio ambiente sejam de patrimônio público, por isso, deve ser assegurado e protegido.

No Brasil o Código Florestal Brasileiro (C.F.B.), Lei nº 4.771 de 15 de setembro de 1965, estabelece que todas as propriedades devam preservar, na Região Sul do Brasil, uma área mínima de vinte por cento de cobertura florestal, a chamada Reserva Legal. A reserva legal visa o uso sustentável dos recursos naturais existentes e da biodiversidade, não sendo permitido o corte raso dessa área e deve ser mantida a cobertura arbórea. No artigo $2^{\circ}$ do C.F.B. encontra-se a regulamentação das áreas de preservação permanente, que são aquelas áreas cobertas ou não por vegetação nativa, com a função ambiental de preservar os recursos hídricos, a paisagem, a estabilidade geológica, a biodiversidade, o fluxo gênico de fauna e flora, proteger o solo e assegurar o bem-estar das populações humanas. A supressão total ou parcial de vegetação em área de preservação permanente requer prévia autorização do Poder Executivo Federal, e só pode ser autorizada em caso de necessidade, devidamente caracterizada em procedimento administrativo próprio, visando a execução de obras ou atividades de utilidade pública ou interesse social, e quando não houver alternativa técnica e locacional ao empreendimento proposto. 
Entretanto, cabe ressaltar que o Código Florestal Brasileiro atualmente encontrase em fase de discussão sobre a reformulação quanto aos valores estipulados para as Áreas de Proteção Permanente e Reserva Legal nas propriedades, todavia as duas incidências legais permanecerão regulamentadas por Lei e continuarão impactando as propriedades rurais e os agricultores familiares.

Para Seidel \& Foleto (2008), os agricultores familiares que se encontram nessas áreas ambientalmente sensíveis irão necessitar produzir para garantir a subsistência de suas famílias e geralmente nessa busca pelo aumento da produtividade esses agricultores causam: o desgaste do solo, pela intensificação na sua exploração; a redução da qualidade e quantidade dos recursos hídricos; o avanço das áreas agrícolas sobre as áreas de preservação, entre outros.

\section{A PERCEPÇÃO AMBIENTAL NA ÓTICA DOS AGRICULTORES FAMILIARES}

A temática ambiental e a busca pelo desenvolvimento sustentável tornaram-se um dos assuntos mais discutidos pela sociedade moderna. Portanto, é de suma importância conhecer e compreender como se forma e qual a percepção ambiental de uma determinada população e as relações existentes entre eles e o meio ambiente, pois a incorporação de uma consciência mais ecológica e projetos mais sustentáveis passa primeiramente pela subjetividade do comportamento e percepções dos indivíduos, ou seja, criam-se significados e visões de mundo que são derivados de vários fatores, sejam eles sociais, políticos, econômicos, culturais, étnicos e outros. Desta forma, para a mudança das percepções é necessário primeiramente que as pessoas mudem suas crenças e atitudes. Para Rohleder et al. (2003) é preciso que os indivíduos modifiquem suas maneiras de agir em todos os aspectos de suas vidas.

A natureza não corresponde ao ciclo econômico, não existe como calcular o valor real do meio ambiente e nenhum cálculo matemático tem como mensurar um valor correto. Deste modo, existe a impossibilidade de mensurar e reduzir os processos ambientais a valores de mercado. O que se tem encontrado para suprir essa limitação são ações, tais como: ações compensatórias, justiça ambiental, entre outros, que buscam minimizar os impactos causados por ações humanas. O valor ambiental depende da 
um despertar de uma maior responsabilidade e conscientização entre os indivíduos e meio ambiente.

Neste trabalho buscou-se compreender a percepção dos agricultores familiares das localidades de Candeia Baixa, Lajeado Paulino, Lajeado Pessegueiro e Rincões, do município de Santa Rosa/RS, quanto à importância da preservação ambiental, focando mais especificamente as áreas de reserva legal e áreas de preservação permanente. Utilizou-se como metodologia a entrevista semi-estruturada com 24 agricultores familiares da região e a observação participante.

Ao analisarmos os resultados obtidos, pode-se notar que todos os agricultores familiares entrevistados acreditam ser importante a preservação ambiental, e que deve ser estimulada a conservação da natureza tanto no meio rural quanto no meio urbano. Para os agricultores familiares não existe uma separação entre rural e urbano, na percepção destes, a natureza é um bem contínuo e coletivo que deve ser garantindo por estes dois, já que não adianta somente um cuidar da parte ambiental, assim não haverá uma sustentabilidade neste processo. Esta percepção pode ser melhor compreendida na fala de um dos agricultores, quando ele diz: "Devemos pensar no futuro (...) nos netos, na população inteira”.

Em relação à legislação ambiental e a sua cobrança no meio rural pode-se notar que os agricultores familiares acreditam que a exigência tanto das áreas de reserva legal quanto as áreas de preservação permanente são importantes para a conservação do meio ambiente, uma das preocupações centrais nas falas é justamente como manter a produção e a preservação na propriedade. Outro aspecto levantado pelos agricultores seria a falta de preocupação ambiental ou a incidência de alguma legislação para os centros urbanos, apontado pelos agricultores com uma dos principais vilões quanto aos cuidados com o meio ambiente. Como fica evidenciado em uma das falas: “(...) mas aqui a gente tudo cuida para não jogar nada no rio ou não cortar árvore, só que o pessoal lá da cidade não cuida, não se importa com a natureza, o rio é cheio de sacola de mercado (...)."

Quando instigado a falar o porquê da necessidade e a importância da preservação/ conservação do meio ambiente, pode-se notar que a uma das maiores preocupações dos agricultores é justamente garantir a qualidade ambiental para seus 
filhos e netos, principalmente o acesso a uma água de qualidade. Fala de um dos agricultores: “(...) pra ter água limpa, para qualidade vida para os filhos e netos”.

Mesmo que muitos agricultores não conheçam o conceito Desenvolvimento sustentável cunhado no relatório Brutland:“(...) aquele desenvolvimento que atende às necessidades do presente sem comprometer as possibilidades de as gerações atenderem às suas próprias". Os mesmos tem a percepção da dimensão deste conceito, e isto pode ser notado em muitas falas, obtidas durante as entrevistas: “(...) é importante manter a natureza pra não destruir mais, pra qualidade de vida e pra fortalecer a agricultura”; “(...) é preciso preservar, porque vira num deserto (...) pra conservar o que temos “(...) pelo futuro do planeta e da família".

Ao buscar conhecer a percepção ambiental e como ela foi adquirida, partiu-se do princípio de que desde o processo da Revolução Verde a agricultura familiar é "invadida" com práticas agrícolas baseadas em altos insumos e na utilização nada sustentáveis dos agroecossistemas, e que desta forma, podia-se ter mudado os valores e as identidades destes agricultores, ou seja, a percepção ambiental quanto à preservação do meio ambiente poderia ser agora percebida como um fator secundário e sem importância para a existência humana, e, portanto, desnecessária.

Ainda, pode-se notar que apesar da grande influência que ainda existe da Revolução Verde na agricultura, a percepção ambiental está sendo adquirida e repassada de forma contínua e sucessiva, seja através de cursos de capacitação ou/e de técnicas menos impactantes ao meio ambiental que são promovidos pelos órgãos de assistências técnicas, cooperativas ou pela Prefeitura. Nas entrevistas fica nítido que a melhor percepção ambiental dos agricultores se dá em dois eixos principais, o primeiro quando o agricultor está engajado em associações, sindicatos e que através destes realiza cursos voltados às questões ambientais, e o segundo eixo é feito pela transmissão e cobrança dos ensinamentos adquiridos pelos filhos, oriundos da Educação Ambiental fornecida pela escola (no caso dos filhos em idade escolar) ou naqueles casos em que os filhos concluíram algum curso técnico em agropecuária e que ao retornar para a casa trazem consigo toda a preocupação ambiental e as novas técnicas aprendidas. Em uma das entrevistas realizadas a agricultora diz exatamente isto que ela e o marido adotaram novas práticas menos poluentes pela cobrança que eles sofrem dos filhos pequenos. 
Assim, a Educação Ambiental visa assegurar o resgate do significado da coevolução homem-natureza, ou seja, uma mudança no pensamento (um novo paradigma) da sociedade contemporânea, promovendo uma maior preocupação e conhecimento das ações e repercussões causadas pelas atividades humanas no meio ambiente natural.

De acordo com Pereira (1993), a educação ambiental deve proporcionar experiências que promovam o contato das pessoas com o mundo, para que desta forma, elas se sensibilizem com os ecossistemas que as envolvem, bem como desenvolver no educando o sentido ético-social diante da problemática ambiental.

Para Jacobi (2003), a educação ambiental pode ser compreendida no sentido mais amplo que é o da educação para a cidadania, sendo elemento determinante para consolidação do que autor denomina de sujeitos cidadãos. Deste modo, o fortalecimento da cidadania irá se concretizar pela possibilidade de cada pessoa ser portadora de direitos e deveres, tornado-se co-responsável pela defesa do bem-estar e da qualidade de vida. A educação para a cidadania é a possibilidade para a motivação e sensibilização dos indivíduos para dinamização da sociedade, promovendo uma nova proposta de sociedade baseada na educação para a participação.

Para promover um presente e futuro mais sustentável e assim garantir a sobrevivência do homem no mundo, torna-se necessário que a percepção existente atualmente sobre a natureza seja transformada. Desta forma, deve-se ter uma "nova" percepção ambiental, ou seja, o homem tem que se ver como mais elo dependente que compõe a grande cadeia que é o meio ambiente, e não mais se colocar como um membro externo e independente. Já que ao ameaçarmos os ecossistemas e sua reprodução estamos ameaçando a nossa própria sobrevivência e continuidade, quanto a espécime nesta cadeia.

Na busca de uma sociedade e de uma economia sustentável é imprescindível que haja informação e educação para todas as esferas da sociedade, para que assim, um novo paradigma seja adotado.

A educação ambiental deve ser vista como aquela educação cujo elemento é de transformação social, integrando a mudança de valores e percepções, fortalecendo as relações e os sujeitos e o exercício da cidadania, promovendo a compreensão do mundo e a sua complexidade. Também como agente de educação, representando uma possibilidade para a motivação da mudança de paradigma e na sensibilização dos 



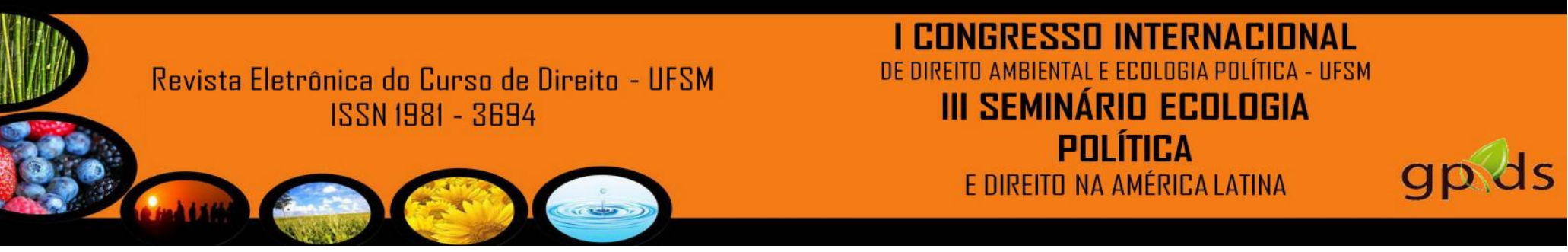

DIEGUES, Antonio Carlos S. Desenvolvimento sustentável ou sociedades sustentáveis da critica dos modelos aos novos paradigmas. São Paulo em Perspectiva, n. 6, p. 2229, jan-jun, 1992.

2001.

O Mito Moderno da Natureza Intocada. $3^{\mathrm{a}}$ ed, São Paulo: Hucitec,

FERNADES, Roosevelt S; et al. Uso da Percepção Ambiental como Instrumento de Gestão em Aplicações Ligadas às Áreas Educacional, Social e Ambiental. 2003. Disponível em> http://www.redeceas.esalq.usp.br/noticias/Percepcao_Ambiental.pdf $<$ Acesso em> 24 de mar. 2010.

FROEHLICH, José Marcos; SILVEIRA, Paulo Roberto Cardoso da; NEUMANN, Pedro. Agricultura familiar e desenvolvimento sustentável. Apostila digital de curso EaD. UAB/UFSM, 2008.

GUZMÁN, Eduardo Sevilla; NAVARRO Manuel González de Molina. Ecosociologia: algunos elementos teoricos para El analisis de La coevolucion social y ecologia em La agricultura. In: Leff, E. (ed), La Complejidad Ambiental, Siglo XXI, Mexico, 54-84. 2000.

IANNI, Aurea María Zóllner. A produção social do ambiente na periferia da metrópole: o caso da capela do Socorro, São Paulo, in: JACOBI, Pedro Roberto. Ciência ambiental: os desafios da interdisciplinaridade. São Paulo: Annablume - Fapesp, 2000 .

JACOBI, Pedro. Educação Ambiental, Cidadania e Sustentabilidade. Cadernos de Pesquisa, $n^{\circ} .118$, março, 2003.

Educação ambiental e o desafio da sustentabilidade socioambiental. O Mundo da Saúde, São Paulo, out/dez 30 (4): 524-531, 2006.

LEFF. Enrique. Saber Ambiental, sustentabilidad, racionalidad, complejidad, poder. México, D.F., Siglo Ventiuno, 1998.

MARQUES, Daniela Vieira. Uma proposta de educação ambiental para áreas verdes: o exemplo do bosque John Kennedy, Araguari, MG. 2001. Monografia. Curso de Graduação em Geografia. Universidade Federal de Uberlândia, 2001. Disponível em> http://www.ufop.br/ichs/conifes/anais/EDU/edu0302.htm> Acesso em> 24 mar. 2012.

MIELGO, Antonio M. Alonso; GUZMÁN, Eduardo Sevilla. El discurso ecotecnocratico de La sostenibilidad. 1994. Disponível em> http://www.cifaed.es/archivos/publicaciones/3.pdf> Acesso em> 24 mar. 2010.

PEREIRA, Antônio Batista. Aprendendo Ecologia Através da Educação Ambiental. Ed. Sagra-DC Luzzatto: Porto Alegre, 1993. 


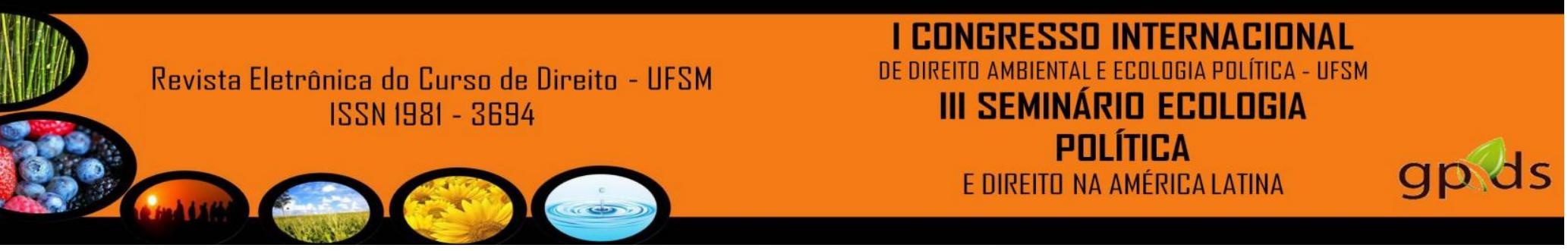

ROHLEDER, Dilnei; GRISON, Antonio José; CALEGARI, Rafael. Percepções Sobre o Desenvolvimento Socioeconômico da Região. Revista de Administração, Frederico Westphalen, Ed. URI, - v. 2, n. 3, nov. 2003.

SEIDEL, Vergílio Seidel, FOLETO Eliane Maria. Propostas de ações em educação ambiental visando a efetivação da legislação ambiental em áreas rurais no município de Santa Maria - Geografia - v. 17, n. 1, jan./jun. 2008 - Universidade Estadual de Londrina, Departamento de Geociências.

ZANETI, Izabel Cristina Bruno Bacellar; SÁ, Lais Mourão. A Educação Ambiental como Instrumento de Mudança na Concepção de Gestão dos Resíduos Sólidos Domiciliares e na Preservação do Meio Ambiente. 2002. Disponível em> http://www.anppas.org.br/encontro_anual/encontro1/gt/sociedade_do_conhecimento/Za neti\%20-\%20Mourao.pdf<Acesso em> 24 de mar. 2012.

WANDERLEY, Maria de Nazareth Baudel. A emergência de uma nova nas sociedades modernas avançadas- o "rural" como espaço singular e ator coletivo. In: Estudos da Sociedade e Agricultura. Rio de Janeiro: CPDA/UFRRJ, n. 15, out. 2000. 